Supporting Information

\title{
An Unconventional Application of Direct Ink Writing: \\ Surface Force-Driven Patterning of Low Viscosity Inks
}

\author{
Guy J. Cordonier, Konstantinos A. Sierros*
}

Flexible Electronics and Sustainable Technologies (FEST) Lab, Department of Mechanical \& Aerospace Engineering, West Virginia University, 1306 Evansdale Drive, Morgantown, West

Virginia 26506, United States

Corresponding Author

*Email: kostas.sierros@mail.wvu.edu,

phone: 304.293 .3420 


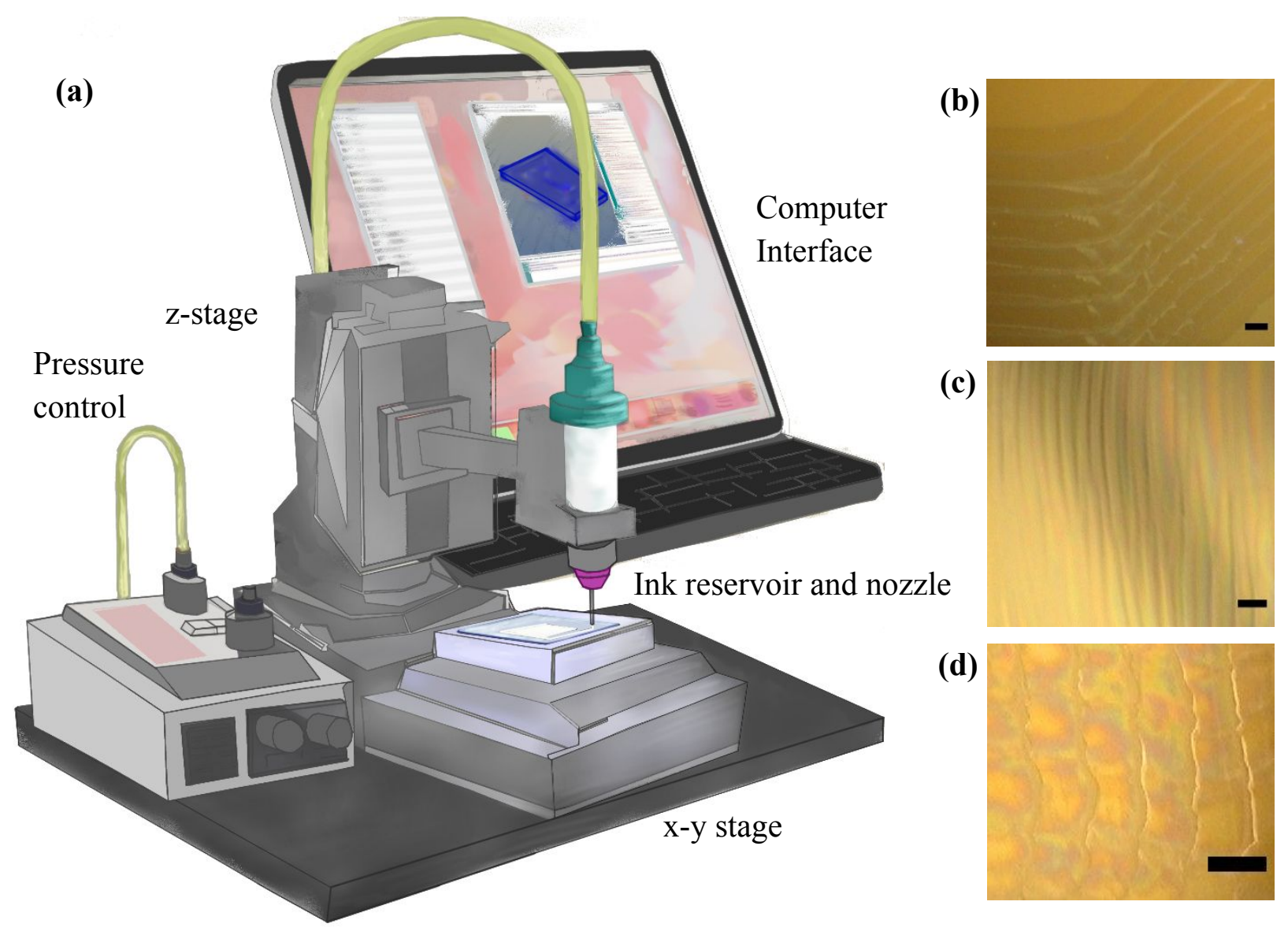

Figure S1. (a) Schematic of the in-house direct ink writing system. Optical images of various films printed with the surface force-drawn direct ink writing method with the ethanol 1:10 ink at $5 \mathrm{~mm} / \mathrm{s}$ and a $100 \mu \mathrm{m}$ nozzle: (b) Parallel lines at a $45^{\circ}$ angle. (c) Meandering lines. (d) Grid pattern formed by printing of two perpendicular meandering films. All scale bars are $1 \mathrm{~mm}$. 


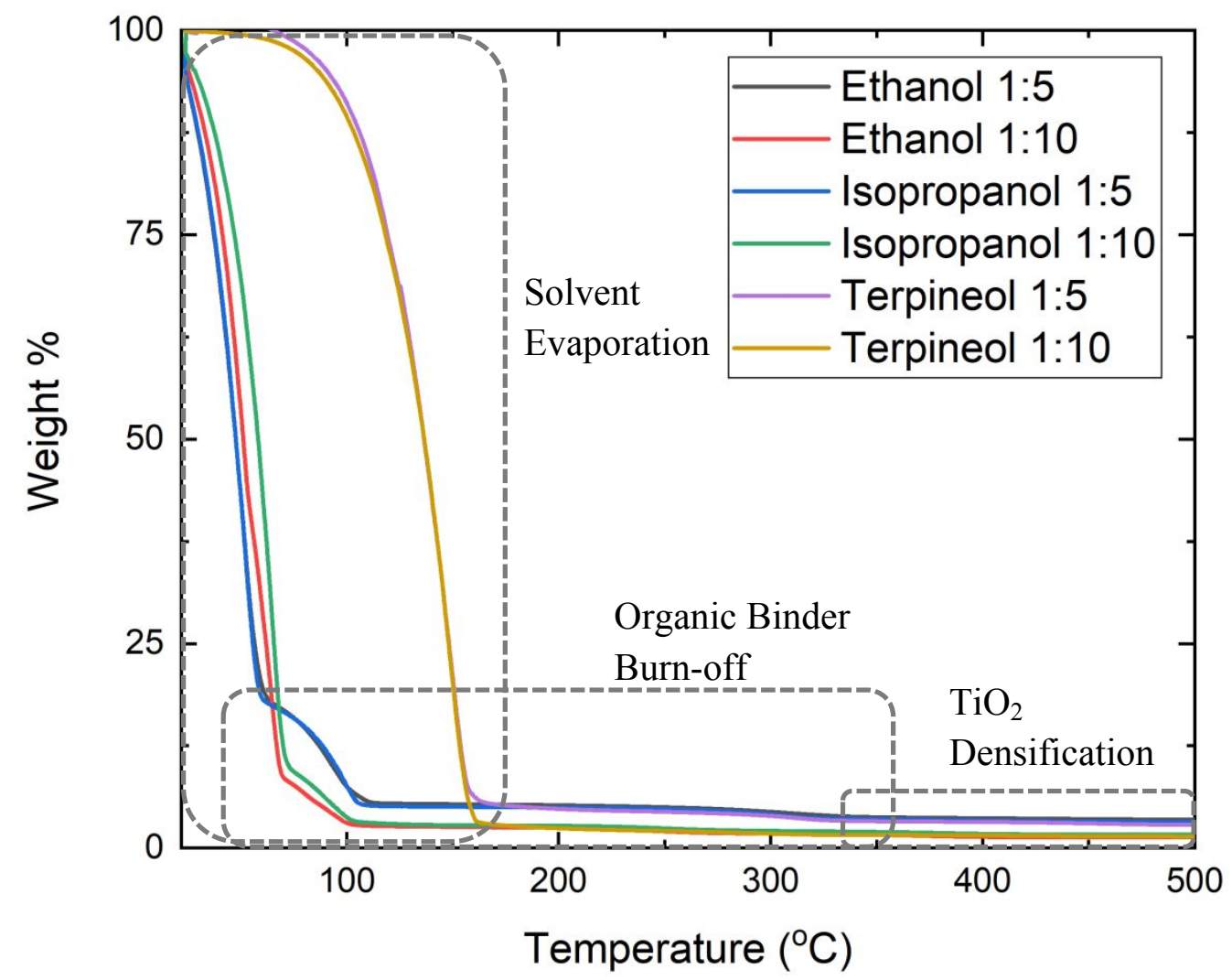

Figure S2. Thermogravimetric Analysis of the titanium dioxide inks. 


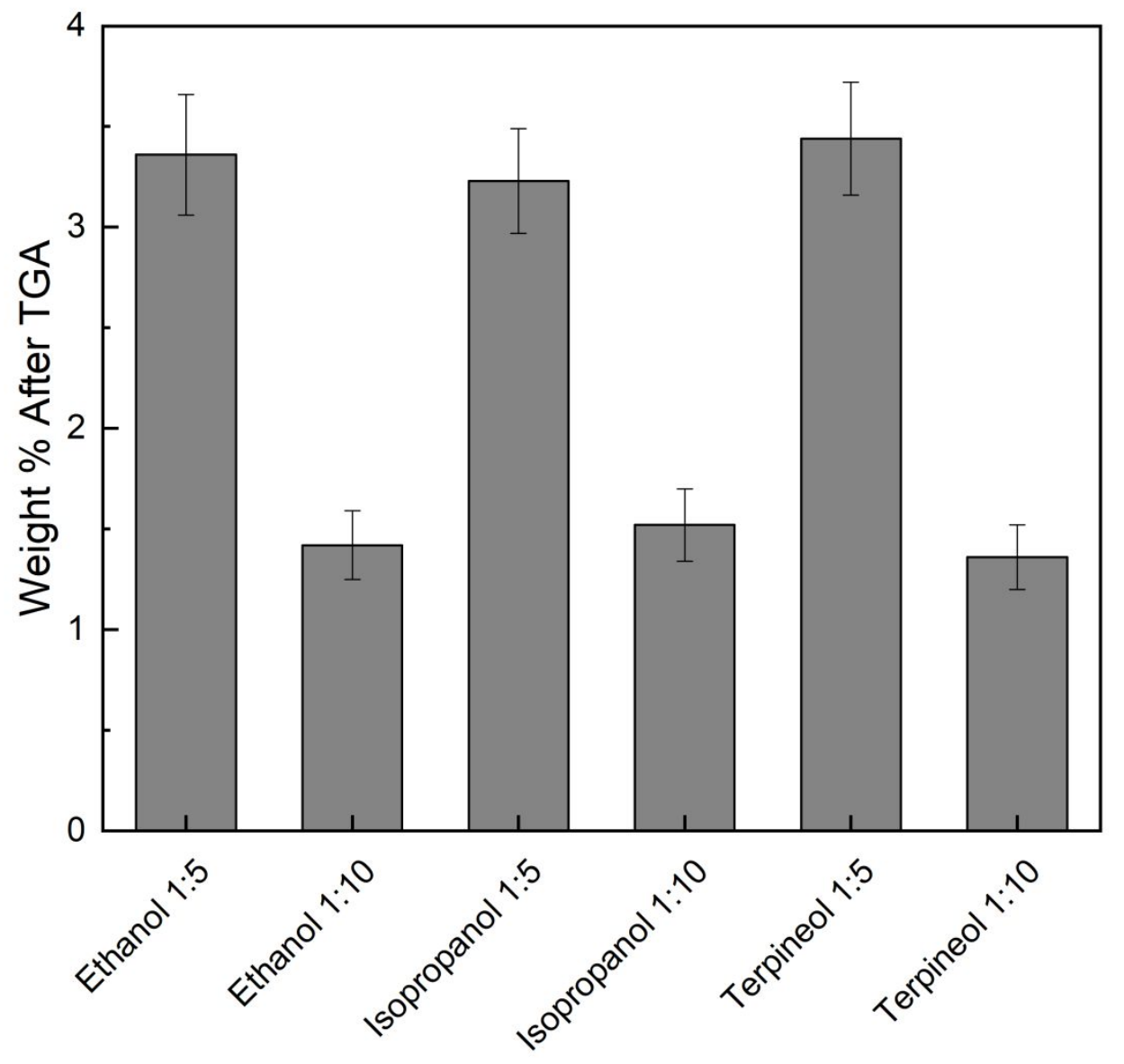

Figure S3. Weight percent remaining of each ink after running in TGA in air from room temperature to $500^{\circ} \mathrm{C}$ at $5^{\circ} \mathrm{C} / \mathrm{min}$, holding at $500^{\circ} \mathrm{C}$ for 30 minutes, then cooling to room temperature at $5^{\circ} \mathrm{C} / \mathrm{min}$. 

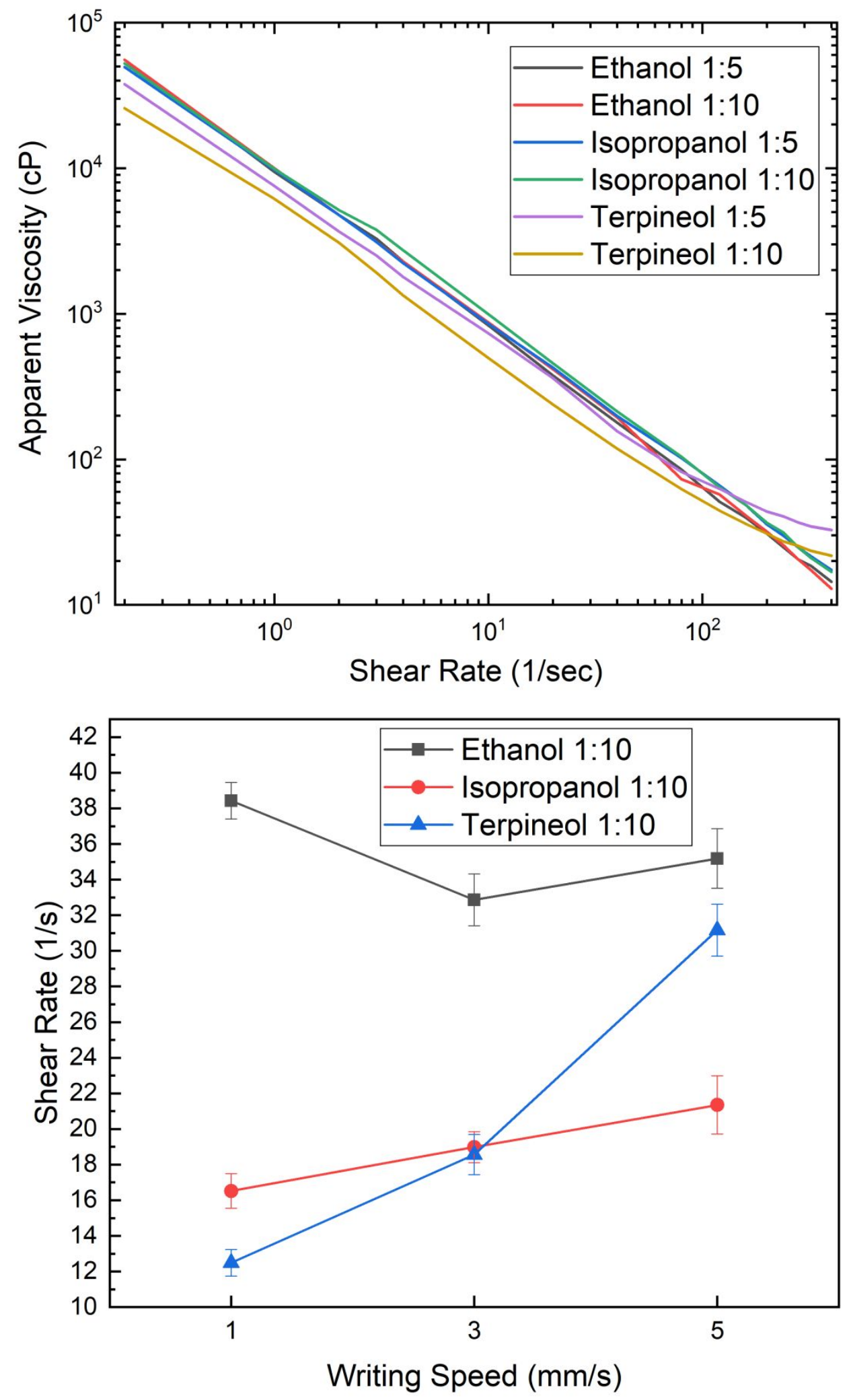

(a) Figure S4. (a) Apparent viscosity measurements of the titanium dioxide inks. (b) Calculated shear rate for the 1:10 inks as a function of writing speed for a $150 \mu \mathrm{m}$ nozzle on glass. 

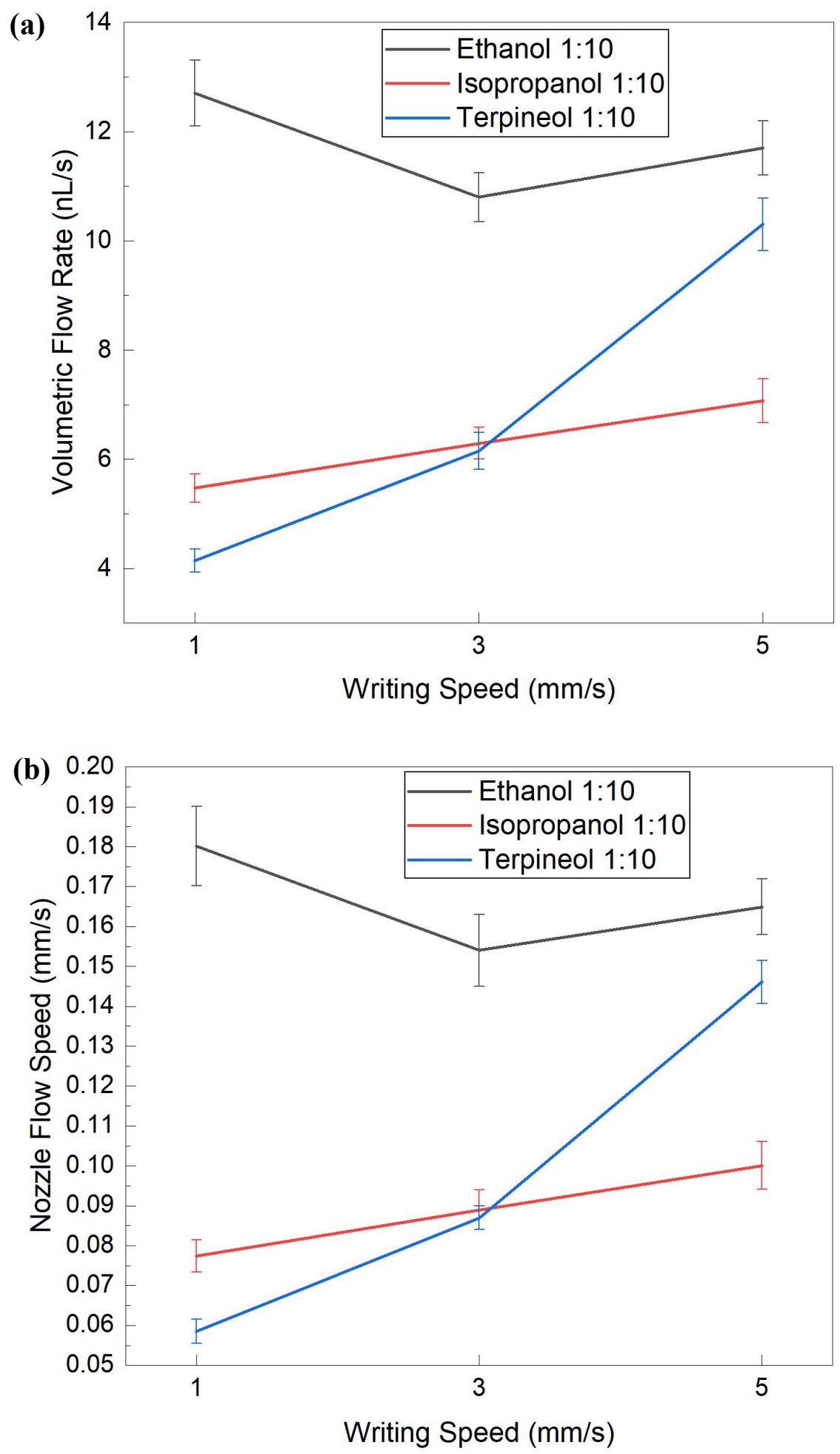

Figure S5. For a $150 \mu \mathrm{m}$ inner diameter stainless steel nozzle: (a) Volumetric flow rate as a function of writing speed for the ethanol 1:10, isopropanol 1:10, and terpineol 1:10 inks. (b) Estimated ink flow speed out of the nozzle for the same inks as a function of writing speed. 


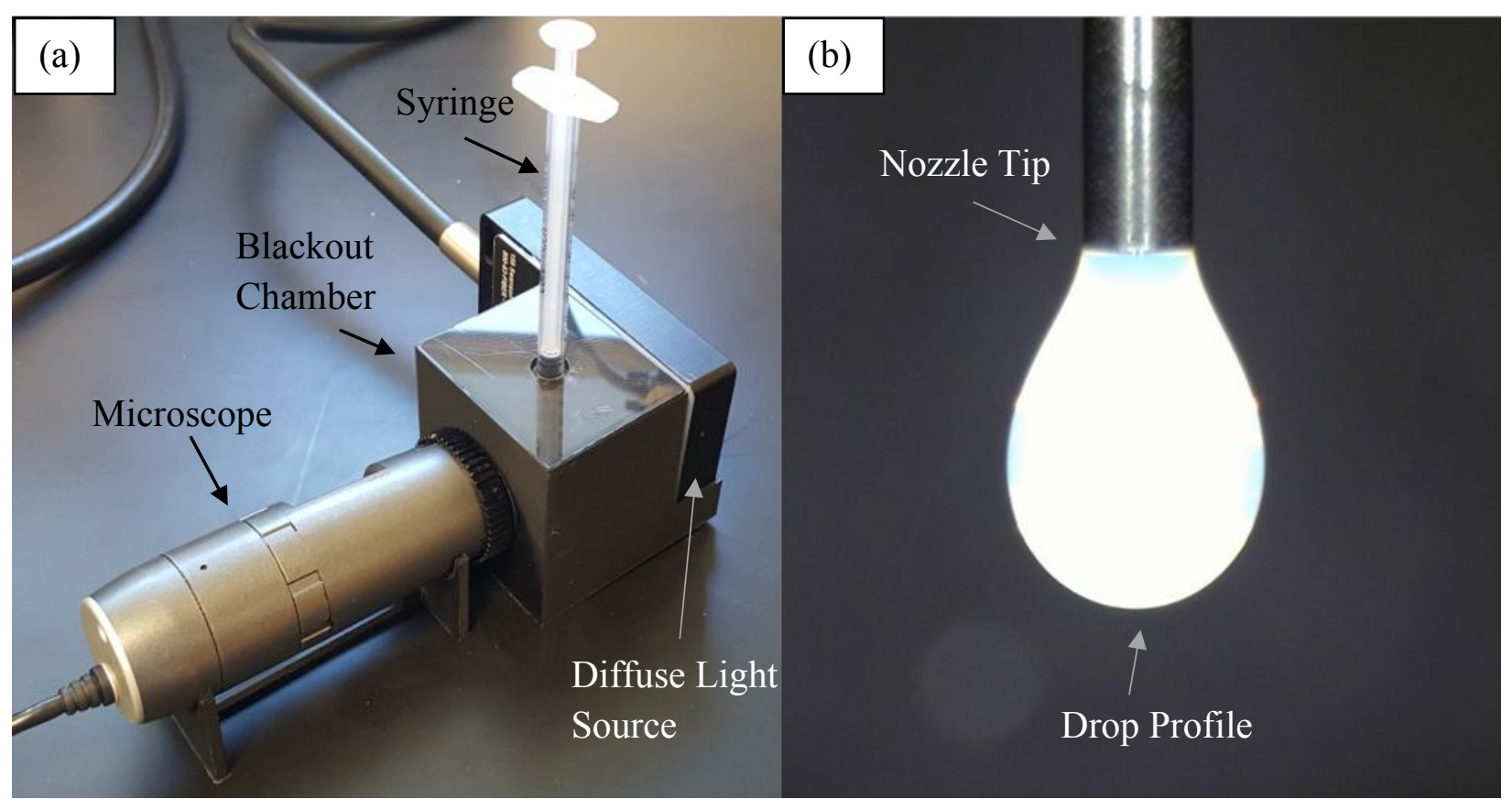

Figure S6. (a) Set-up for pendant drop tensiometry measurements. (b) Image of a pendant drop of ethanol 1:10 ink taken by the microscope used in the surface tension measurement. 


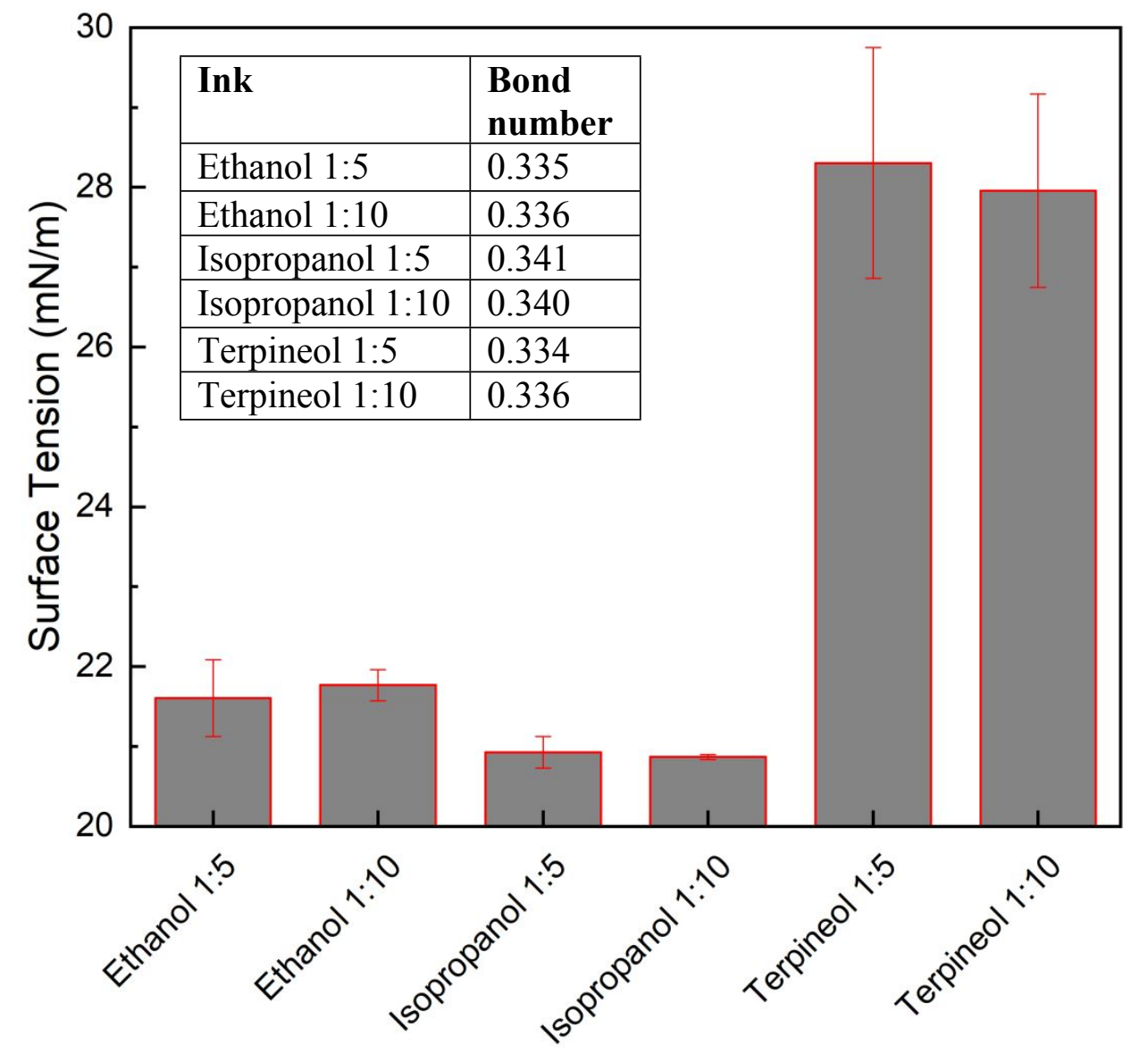

Figure S7. Surface tension values of the titanium dioxide inks obtained from pendant drop tensiometry. Bond numbers for each ink are reported in the inset. 


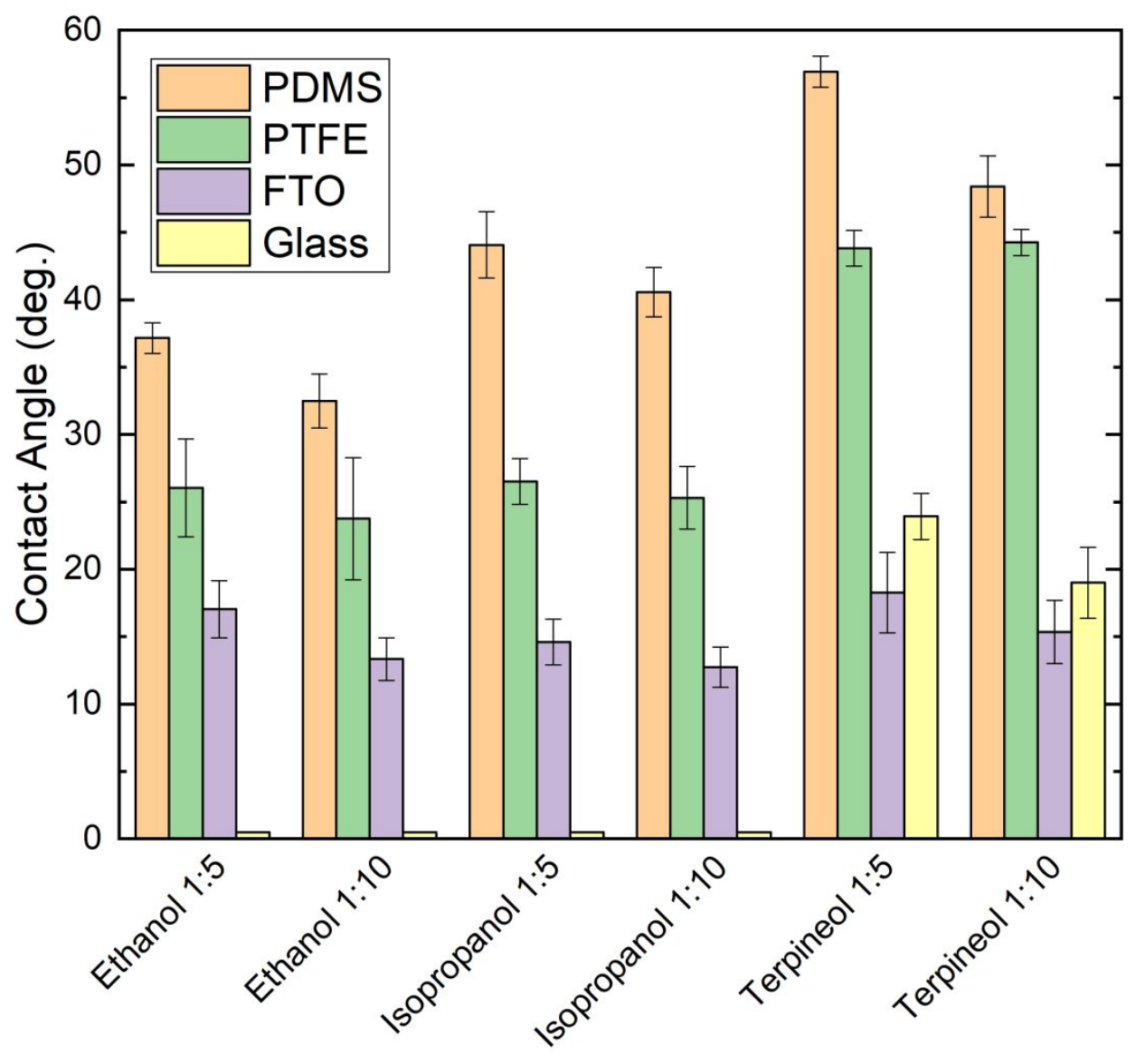

Figure S8. Contact angle for titanium dioxide inks on various substrates. 


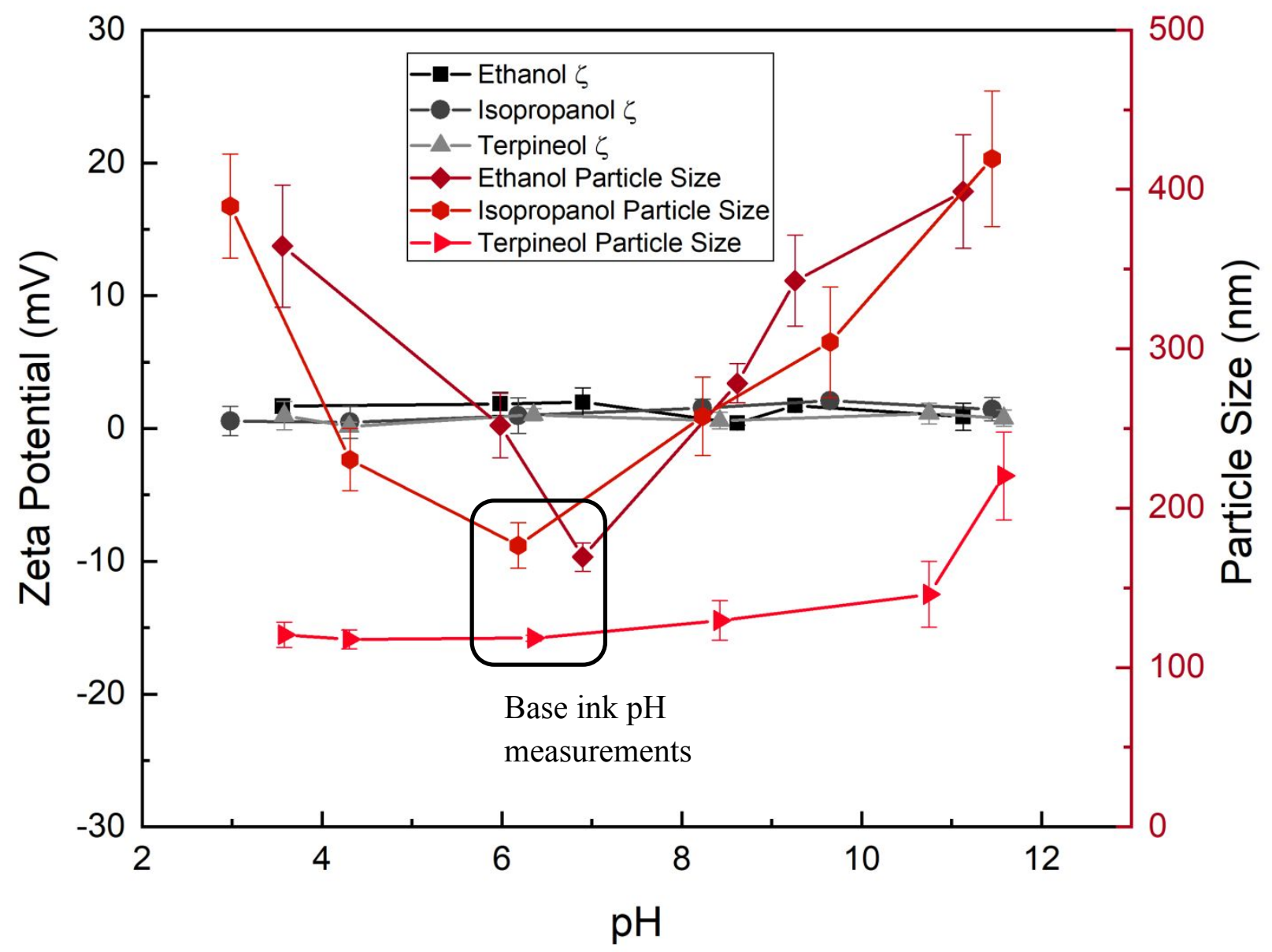

Figure S9. Zeta potential and particle size measurements for the ethanol, isopropanol, and terpineol inks. The solutions were made more basic by adding potassium hydroxide, and more acidic by adding hydrochloric acid. All inks exhibited approximately $0 \mathrm{mV}$ for zeta potential, $\zeta$. Increases in particle size measurements were observed as each ink was made more basic. However, as the inks were made more acidic, the ethanol and isopropanol inks saw an increase in particle size, whereas the terpineol ink particle size remained constant. The base ink $\mathrm{pH}$ measurements have been highlighted by the black box. 
(a)

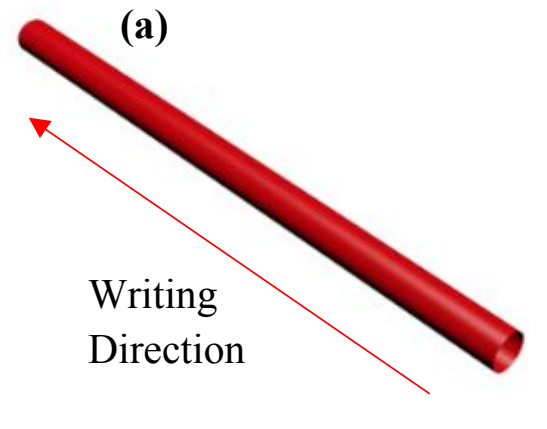

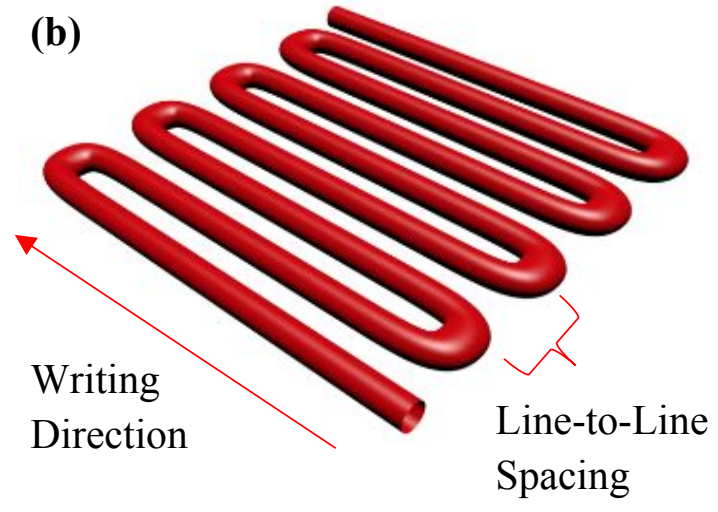

(c)

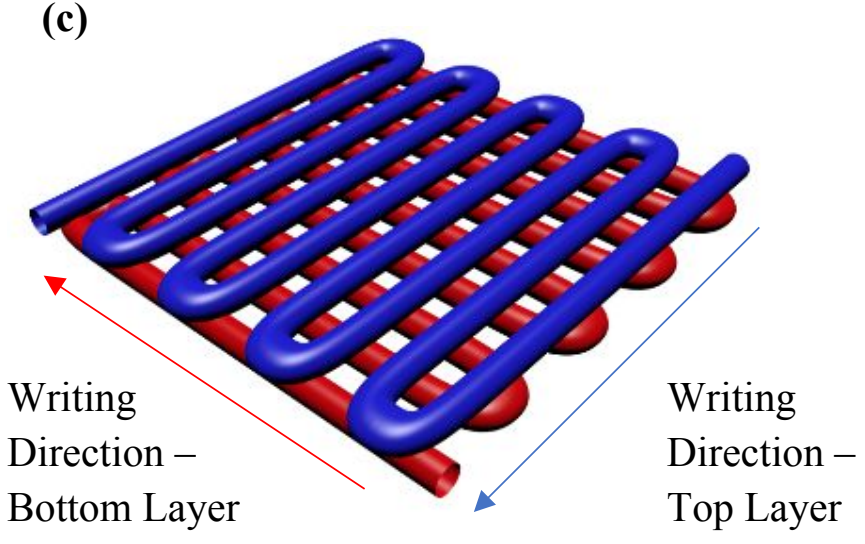

Figure S10. 3D renderings of the nozzle tool path used to generate (a) singular lines, (b) singlelayer meandering film, and (c) double-layer grid film. 


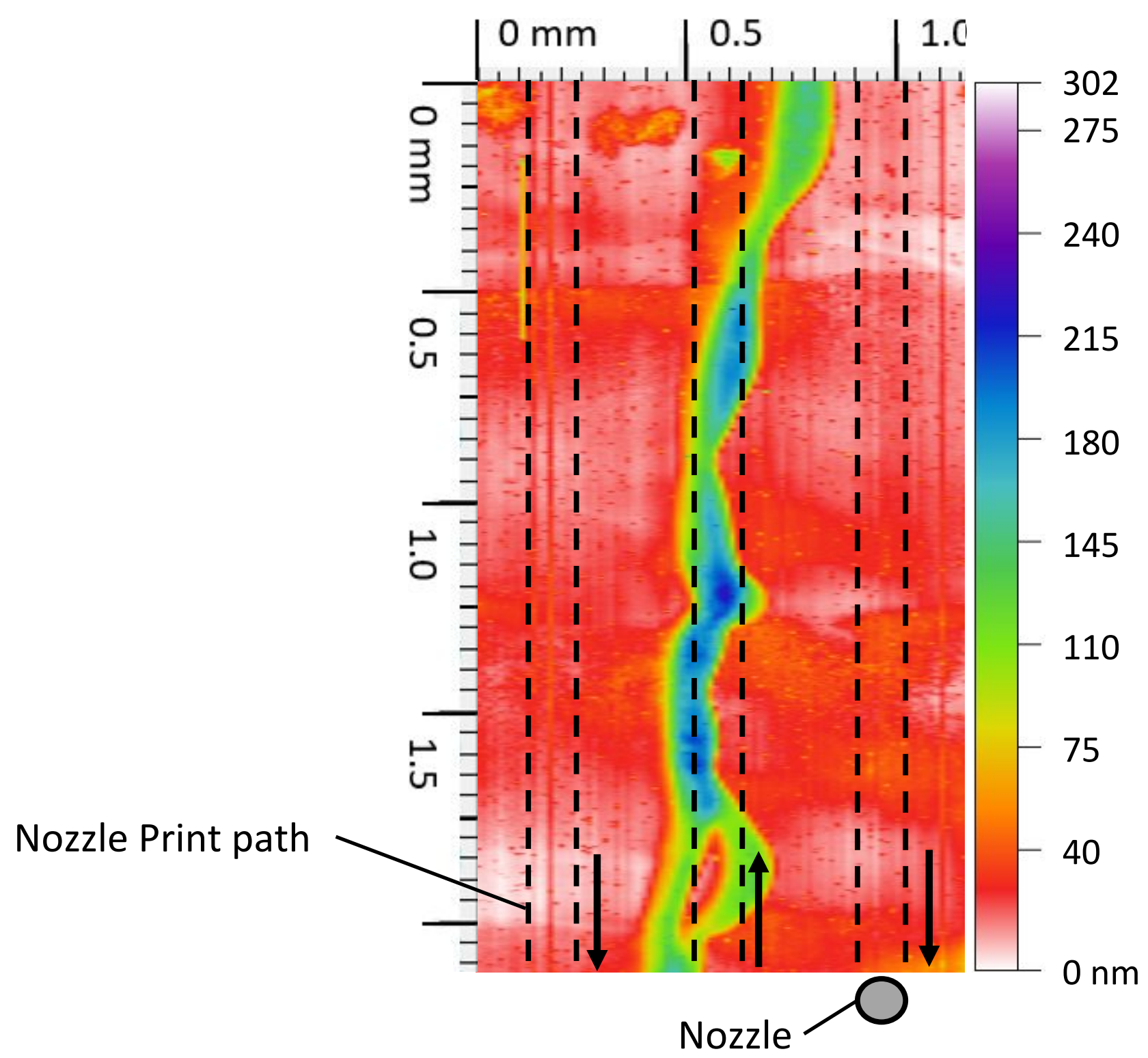

Figure S11. A profilometer scan of a film printed with the ethanol 1:10 ink at $5 \mathrm{~mm} / \mathrm{s}$ on glass with 450 um line-to-line spacing. The nozzle print path is drawn on top (dashed lines), illustrating the deviation between toolpath and hill position, as well as the diffusion of ink from adjacent pathways into the hill. 

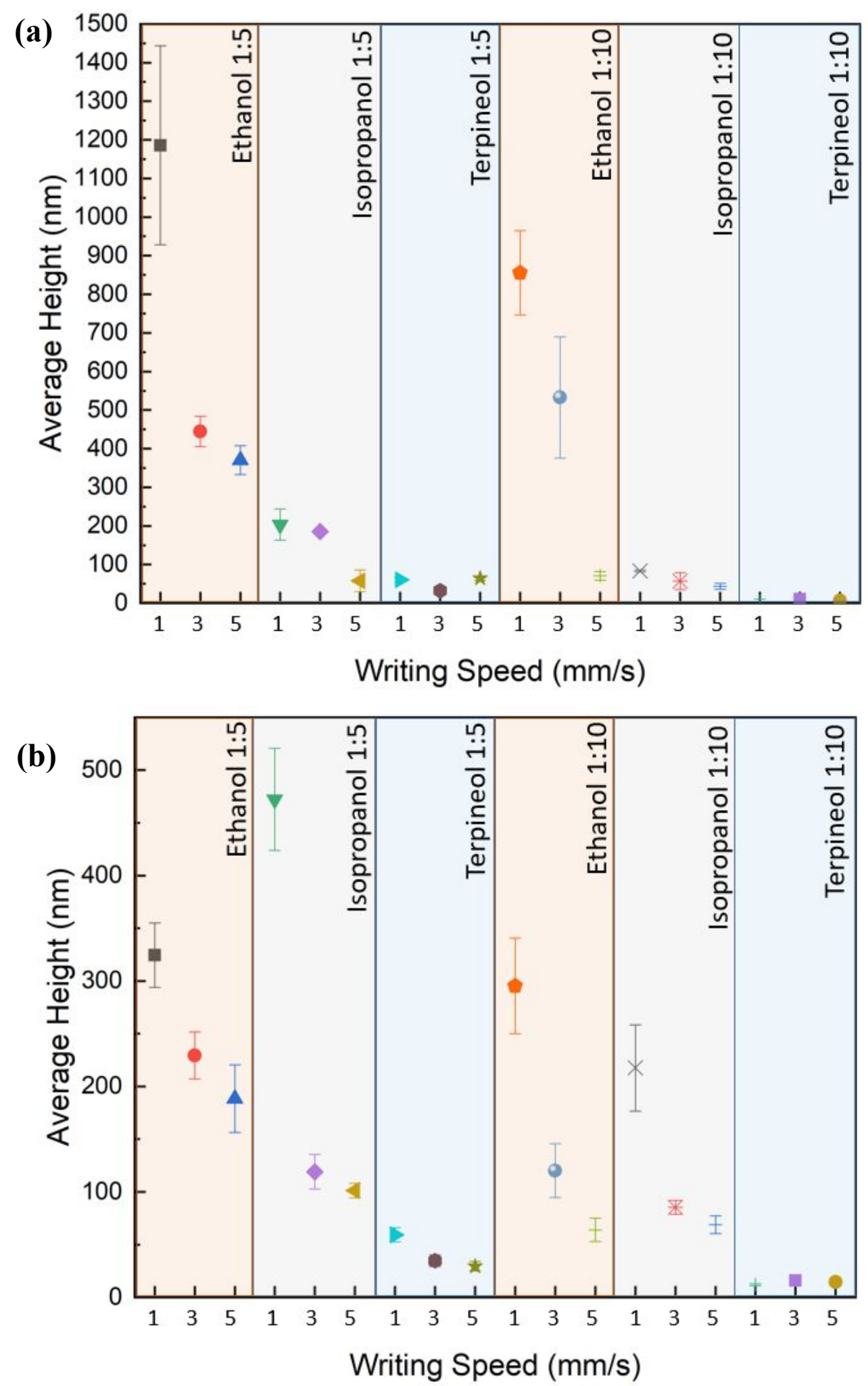

Figure S12. Average heights of cross-sectional profiles of lines of inks directly written on substrates of (a) FTO and (b) $\mathrm{TiO}_{2}$-FTO. 


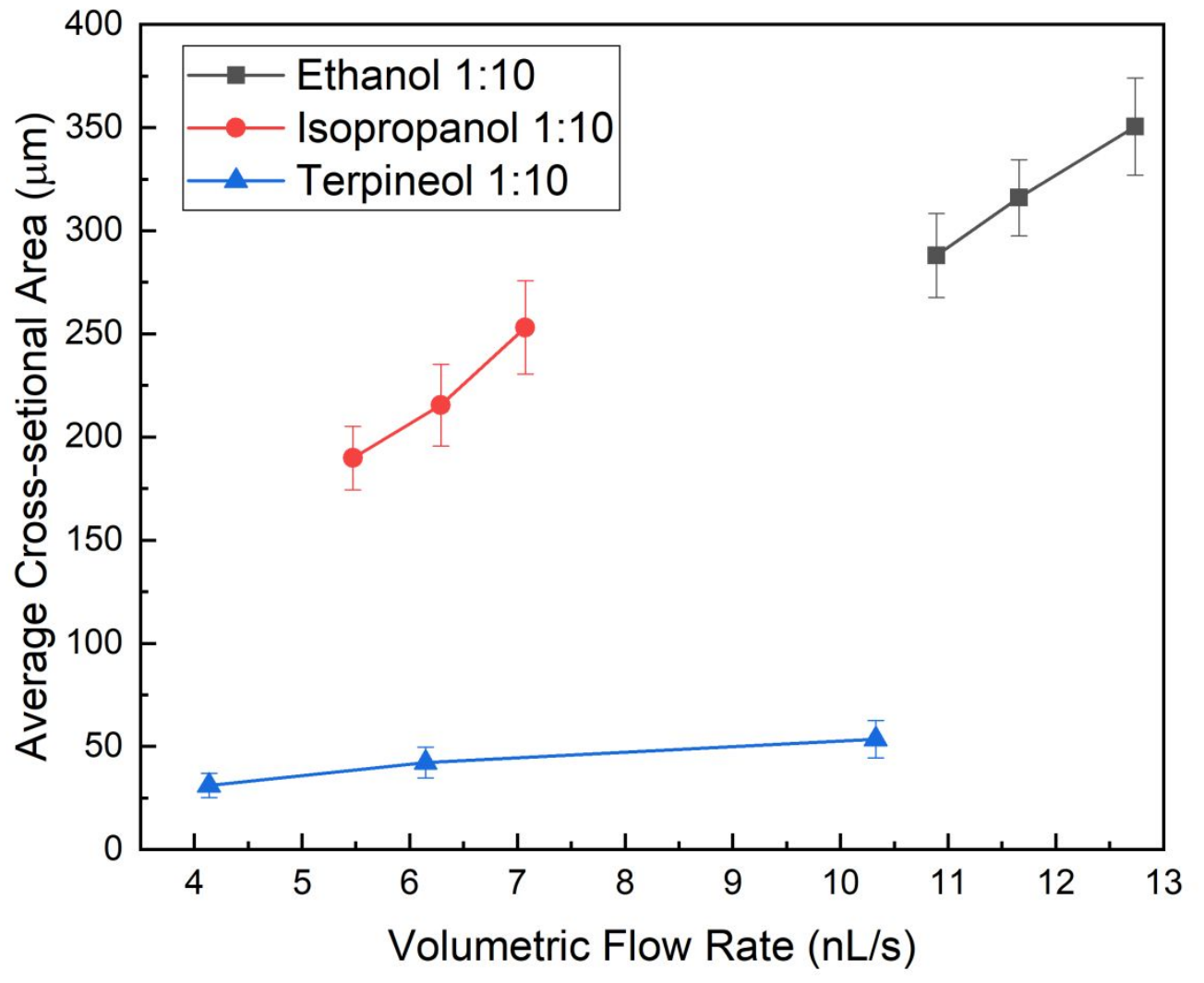

Figure S13. Average cross-sectional area as a function of flow rate for the 1-10 inks printed on glass at writing speeds of 1,3 , and $5 \mathrm{~mm} / \mathrm{s}$. 
Table S1. AFM measurements of double-layer grid patterns of the ethanol 1-10 ink.

\begin{tabular}{|l|c|c|c|}
\hline & $\begin{array}{c}\text { Writing } \\
\text { Speed }\end{array}$ & \multicolumn{2}{|c|}{ Roughness, Sa } \\
\hline Line-to-line spacing & & Hills & Valleys \\
\hline $\mathbf{( \mu m )}$ & $(\mathrm{mm} / \mathrm{s})$ & $(\mathrm{nm})$ & $(\mathrm{nm})$ \\
\hline $\mathbf{3 0 0}$ & 3 & $18.38 \pm 0.75$ & $17.39 \pm 0.53$ \\
\hline & 5 & $16.12 \pm 2.03$ & $14.30 \pm 1.37$ \\
\hline \multirow{2}{*}{$\mathbf{4 5 0}$} & 7 & $14.77 \pm 0.69$ & $14.56 \pm 0.72$ \\
\hline & 3 & $15.71 \pm 1.99$ & $11.93 \pm 0.73$ \\
\hline \multirow{2}{*}{$\mathbf{6 0 0}$} & 5 & $14.03 \pm 1.02$ & $12.55 \pm 0.81$ \\
\hline & 7 & $13.00 \pm 0.59$ & $11.53 \pm 0.13$ \\
\hline & 3 & $12.34 \pm 0.46$ & $10.68 \pm 0.96$ \\
\hline & 5 & $12.75 \pm 1.69$ & $12.17 \pm 0.49$ \\
\hline & 7 & $11.62 \pm 1.23$ & $11.78 \pm 0.43$ \\
\hline
\end{tabular}



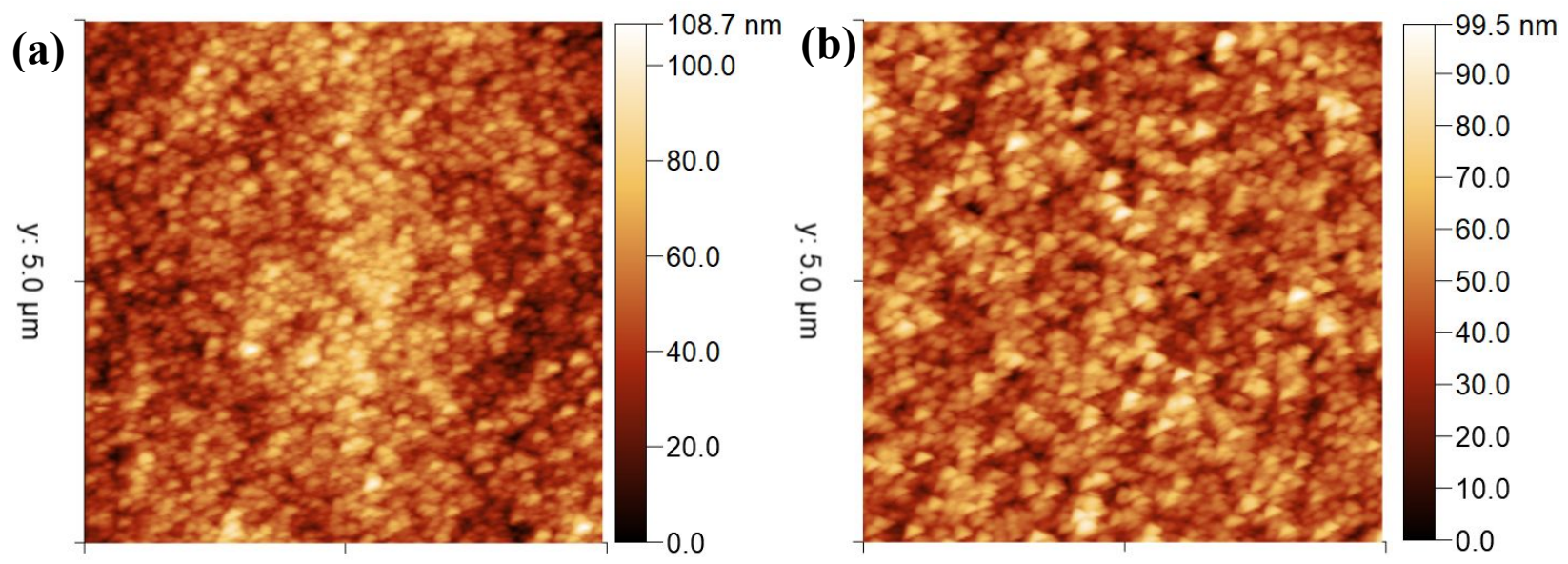

$\mathrm{x}: 5.0 \mu \mathrm{m}$

$\mathrm{x}: 5.0 \mu \mathrm{m}$
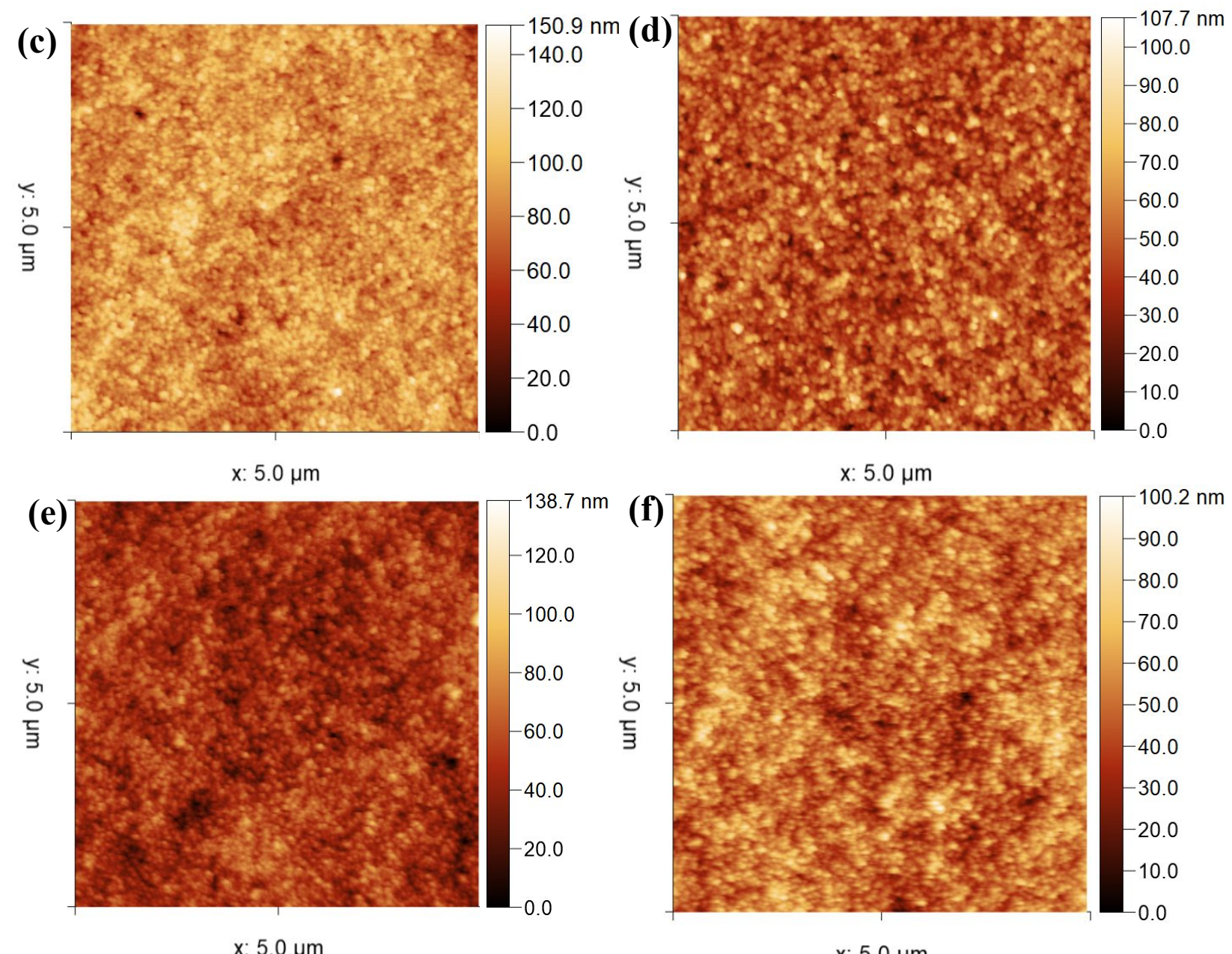

$\mathrm{x}: 5.0 \mu \mathrm{m}$

x: $5.0 \mu \mathrm{m}$

Figure S14. $5 \mu \mathrm{m}$ x $5 \mu \mathrm{m}$ scans of the DIW grids. (a) Hill of a $300 \mu \mathrm{m}$ line-to-line spaced grid, written at $5 \mathrm{~mm} / \mathrm{s}$. (b) Valley of a $300 \mu \mathrm{m}$ line-to-line spaced grid, written at $5 \mathrm{~mm} / \mathrm{s}$. (c) Hill of a $450 \mu \mathrm{m}$ line-to-line spaced grid, written at $7 \mathrm{~mm} / \mathrm{s}$. (d) Valley of a $450 \mu \mathrm{m}$ line-to-line spaced grid, written at $7 \mathrm{~mm} / \mathrm{s}$. (e) Hill of a $600 \mu \mathrm{m}$ line-to-line spaced grid, written at $3 \mathrm{~mm} / \mathrm{s}$. (f) Hill of a $600 \mu \mathrm{m}$ line-to-line spaced grid, written at $3 \mathrm{~mm} / \mathrm{s}$. 
Table S2. Apparent degradation rate $\left(k_{\text {app }}\right)$ of methylene blue (aq) for meandering films of titanium dioxide exposed to ultraviolet radiation. $\varphi$, correction factor $c, \varphi^{*}$, and roughness measurements of the films are also listed.

\begin{tabular}{|c|c|c|c|c|c|c|c|}
\hline & $\begin{array}{c}\text { Writing } \\
\text { Speed }\end{array}$ & $k_{\text {app }} \times 10^{-3}$ & $\begin{array}{l}\text { Degradation } \\
\text { efficiency at } \\
240 \mathrm{~min}\end{array}$ & $\varphi$ & $c$ & $\varphi^{*}$ & $\begin{array}{c}\text { AFM } \\
\text { roughness }\end{array}$ \\
\hline Sample & $(\mathrm{mm} / \mathrm{s})$ & $\left(\min ^{-1}\right)$ & $(\%)$ & $\left(\mathrm{m}^{2} / \mathrm{g}\right)$ & & $\left(\mathrm{m}^{2} / \mathrm{g}\right)$ & $(\mathrm{nm})$ \\
\hline Blank & --- & $0.106 \pm 0.002$ & $2.2 \pm 0.3$ & --- & --- & --- & --- \\
\hline \multirow{3}{*}{$\begin{array}{l}\text { Ethanol } \\
1: 10\end{array}$} & 1 & $1.965 \pm 0.023$ & $38.1 \pm 2.1$ & 0.065 & 1.12 & $0.072 \pm 0.006$ & $13.47 \pm 0.7$ \\
\hline & 3 & $1.893 \pm 0.017$ & $29.0 \pm 1.2$ & 0.183 & 1.09 & $0.199 \pm 0.016$ & $12.82 \pm 0.4$ \\
\hline & 5 & $1.802 \pm 0.009$ & $35.3 \pm 1.6$ & 0.251 & 1.09 & $0.274 \pm 0.024$ & $12.68 \pm 0.5$ \\
\hline \multirow{3}{*}{$\begin{array}{l}\text { Isopropanol } \\
1: 10\end{array}$} & 1 & $1.743 \pm 0.023$ & $34.4 \pm 1.7$ & 0.117 & 1.10 & $0.130 \pm 0.009$ & $12.85 \pm 0.3$ \\
\hline & 3 & $1.521 \pm 0.017$ & $31.0 \pm 0.9$ & 0.289 & 1.11 & $0.320 \pm 0.011$ & $13.35 \pm 0.4$ \\
\hline & 5 & $1.210 \pm 0.011$ & $25.5 \pm 1.3$ & 0.370 & 1.09 & $0.402 \pm 0.019$ & $12.32 \pm 0.6$ \\
\hline \multirow{3}{*}{$\begin{array}{l}\text { Terpineol } \\
1: 10\end{array}$} & 1 & $0.392 \pm 0.022$ & $9.9 \pm 0.7$ & 0.080 & 1.09 & $0.087 \pm 0.005$ & $12.40 \pm 0.8$ \\
\hline & 3 & $0.180 \pm 0.015$ & $4.2 \pm 0.6$ & 0.158 & 1.10 & $0.174 \pm 0.013$ & $13.90 \pm 0.5$ \\
\hline & 5 & $0.136 \pm 0.008$ & $3.9 \pm 0.5$ & 0.131 & 1.12 & $0.146 \pm 0.010$ & $13.94 \pm 0.6$ \\
\hline
\end{tabular}

Pseudo-first order kinetics were assumed and used to calculate $k_{\text {app }}$ for the films submerged in methylene blue (aq) and exposed to ultraviolet radiation. The Beer-Lambert Law was used to calculate the degradation efficiency of the methylene blue dye,

$$
\ln \left(\frac{C_{o}}{C_{t}}\right)=k_{\text {app }} * t
$$

where $\mathrm{C}_{\mathrm{o}}$ is the initial concentration, $\mathrm{C}_{\mathrm{t}}$ is the concentration at time $t$, and $k_{\text {app }}$ is the apparent degradation rate constant. kapp can be determined graphically as the slope of the linear fit of $l n$ $\left(\frac{C_{o}}{C_{t}}\right)$ as a function of time (see Figure S15). 


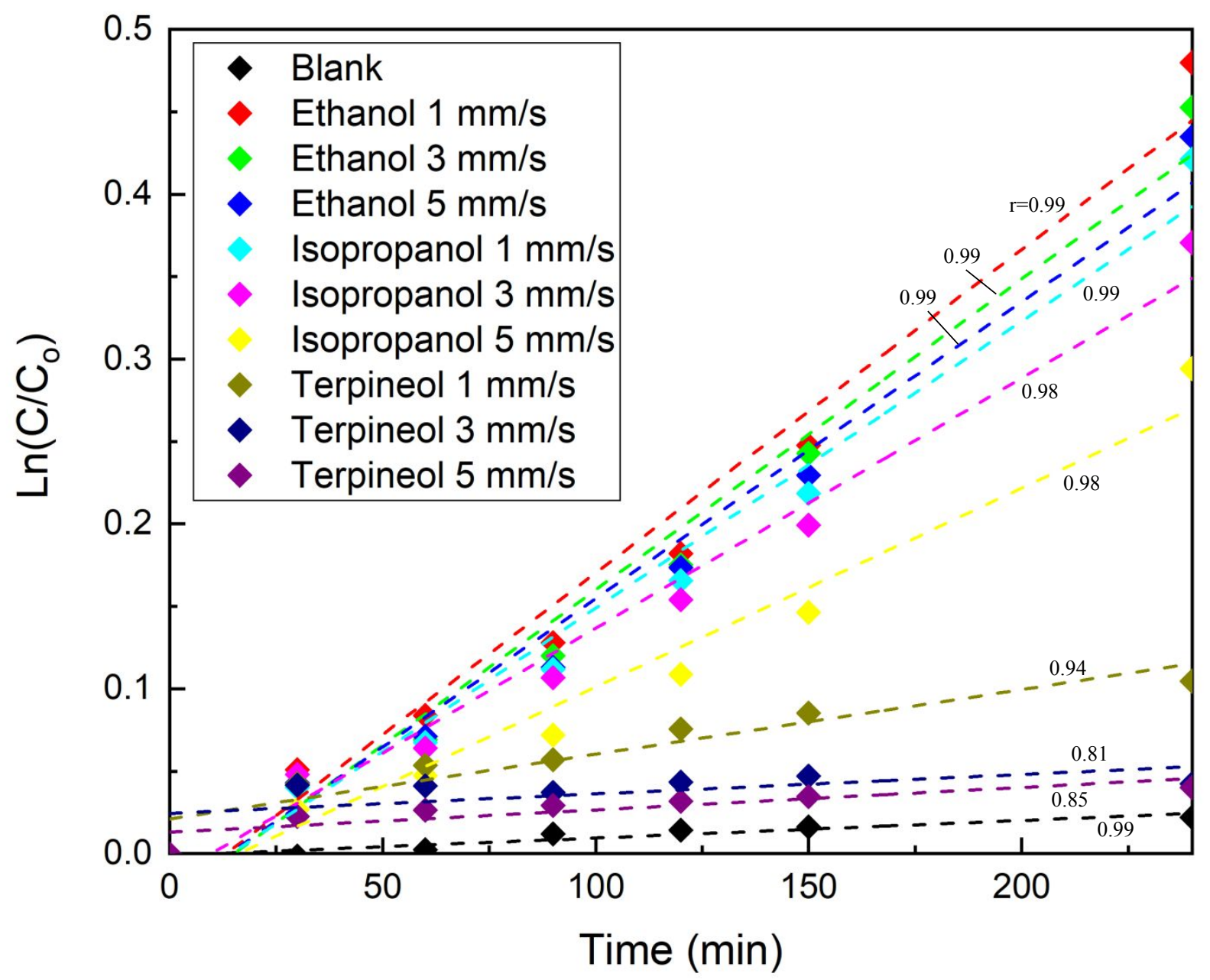

Figure S15. Change in concentration of Methylene Blue as a function of time for films submerged in Methylene Blue (aq) and exposed to ultraviolet radiation. The correlation coefficient (Pearson's R) is plotted for each fit. 